Classification

Physics Abstracts

$61.16 \mathrm{D}-68.48$

\title{
Interface and interphase in carbon-epoxy composite materials. Study by transmission electron microscopy
}

\author{
Michèle Guigon \\ Division “Polymères et Composites", Université de Technologie de Compiègne, B.P. 649, \\ 60206 Compiègne Cedex, France
}

(Received October 26, 1990; accepted December 17, 1990)

\begin{abstract}
Résumé. - Dans les matériaux composites, les propriétés mécaniques dépendent principalement des propriétés des fibres et de la matrice. Cependant certains résulats expérimentaux ne peuvent être expliqués si nous n'impliquons pas le rôle joué par l'interface fibre-matrice. Industriellement les fibres subissent un traitement de surface oxydant. Elles sont ensuite ensimées. Comme l'adhésion fibre matrice dépend de tous ces paramètres, nous avons caractérisé l'interface dans le cas de traitements de surface connus. L'étude des jonctions fibres-matrice a été effectuée par microscopie électronique par transmission (franges de réseau).
\end{abstract}

\begin{abstract}
In composite materials, mechanical properties depend mainly on fibre and matrix properties. However many experimental results cannot be explained unless role played by the interface is considered. In the manufacturing process, composite materials are made up of fibres which are subjected to a surface treatment (oxidizing treatment). In order to improve the adhesion between fibres and matrix, they are coated with a sizing product whose composition is complex. Since fibre-matrix adhesion is related to these parameters, we characterized the interface in the case of well-known surface treatments. We studied the fibre-matrix junctions by the lattice-fringe method (TEM).
\end{abstract}

\section{Introduction.}

At the present time, the specific developments of composite properties are governed by the optimization of surface treatments and sizing of the fibres. However, it is obvious that the interfacial phenomena depend on the surface morphology of fibres. In a first step we have studied the microtexture of carbon fibres, then the fibre-matrix junction by using Transmission Electron Microscopy (TEM) methods. The relationship between the features of the fibre surface and fibre-matrix adhesion is discussed. 


\section{Experimental techniques.}

The interfacial phenomena studied in this work consist of structural details at the nanometre scale. In order to observe this fine structure we need to use a high resolution mode for which phase-contrast effects are important. For our studies, we used the interference of the undeviated beam and the (002) beam diffracted by the carbon layers of the fibre. However the resolution is limited by the attenuation of the contrast-transfer function $[1,2]$. For phase structures, the attenuation is mainly characterized by the aberration function $\chi(q)$.

$$
\chi(q)=\pi\left(1 / 2 C_{\mathrm{s}} \lambda^{3} q^{4}-\Delta z \lambda q^{2}\right)
$$

where $q$ is the spatial frequency, $C_{\mathrm{s}}$ is the spherical aberration, $\lambda$ is the wavelength, and $\Delta z$ is the defocusing.

The defocusing $(\Delta z)$ and the spherical aberration $\left(C_{\mathrm{s}}\right)$ therefore, play an important role in the electron microscope. The shape of the aberration function for different values of defocus shows that a phase shift of $\pm \pi / 2$ (necessary for phase contrast) cannot be obtained simultaneously for all scattering angles. Only for a limited range of scattering angles or their corresponding spatial frequencies $q$ will be desired phase shift for $\chi(q)$ be achieved. Maximum positive phase contrast is obtained for the so-called Scherzer conditions.

In our work $\left(2.3 \mathrm{~nm}^{-1}<q<3.3 \mathrm{~nm}^{-1}\right)$ we are near these conditions for $\Delta z=72 \mathrm{~nm}$. The graph of the function $\sin \chi$ is represented in figure 1 .

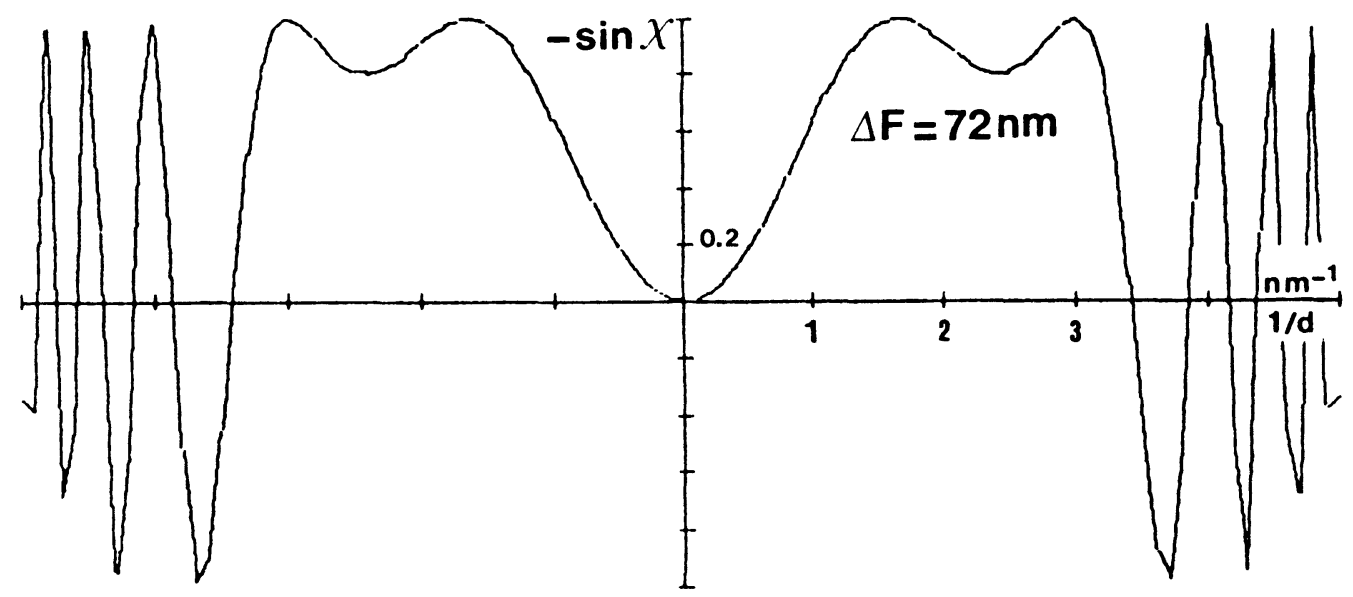

Fig. 1. - Transfert function with $\Delta z=72 \mathrm{~nm}$.

Phase contrast effects decrease with increasing specimen thickness owing to the attenuation of the incident wave amplitude. In order to consider the specimen as a weak phase object, it should be very thin. This sections perpendicular to the fibre axis have been obtained with an ultramicrotomy method by using a diamond knife (50 to $80 \mathrm{~nm}$ in thickness). 


\section{Surface treatments.}

The surface treatments were commercial treatments (oxidizing treatments) or anodic treatments (oxidizing and non-oxidizing treatments) carried out at ONERA [3, 4]. In the latter case, all the samples have been treated with a potential lower than the ionisation potential of water $(1.75 \mathrm{~V})$. The treated carbon fibres have been used without sizing.

Surface treatments are described as follows:

- oxidizing surface treatment with sizing-Courtaulds XAS fibres-commercial sample

- oxidizing surface treatment (aqueous solution of $\left(\mathrm{NH}_{4}\right)_{2} \mathrm{SO}_{4}$ - anodic treatment) without sizing-Courtaulds XAU fibres

- non oxidizing surface treatments (aqueous solution of tetramine hexamethylene, urea) without sizing-Courtaulds XAU fibres

\section{Experimental data.}

4.1 MiCRoteXtURE OF CARBON FIBRES. - Carbon fibres are made up of sets of turbostratic stacks of aromatic layers lying approximately parallel to the fibre axis AA' (basic microtextural units: BMU) with rotational disorder perpendicular to their plane [5,6] (Fig. 2a). They are linked together around the fibre axis and their reciprocal lattice is given in figure $2 \mathrm{~b}$. The parallel stacking yields $00 l$ Bragg reflections, whereas the rotational disorder produces hk cylinders. For transverse sections, an 002 scattered beam is produced by planes parallel to the incident electron beam to within $1^{\circ}$ or $2^{\circ},(10)$ and (11) rings are the result of diffraction of carbon layers in rotational disorder.

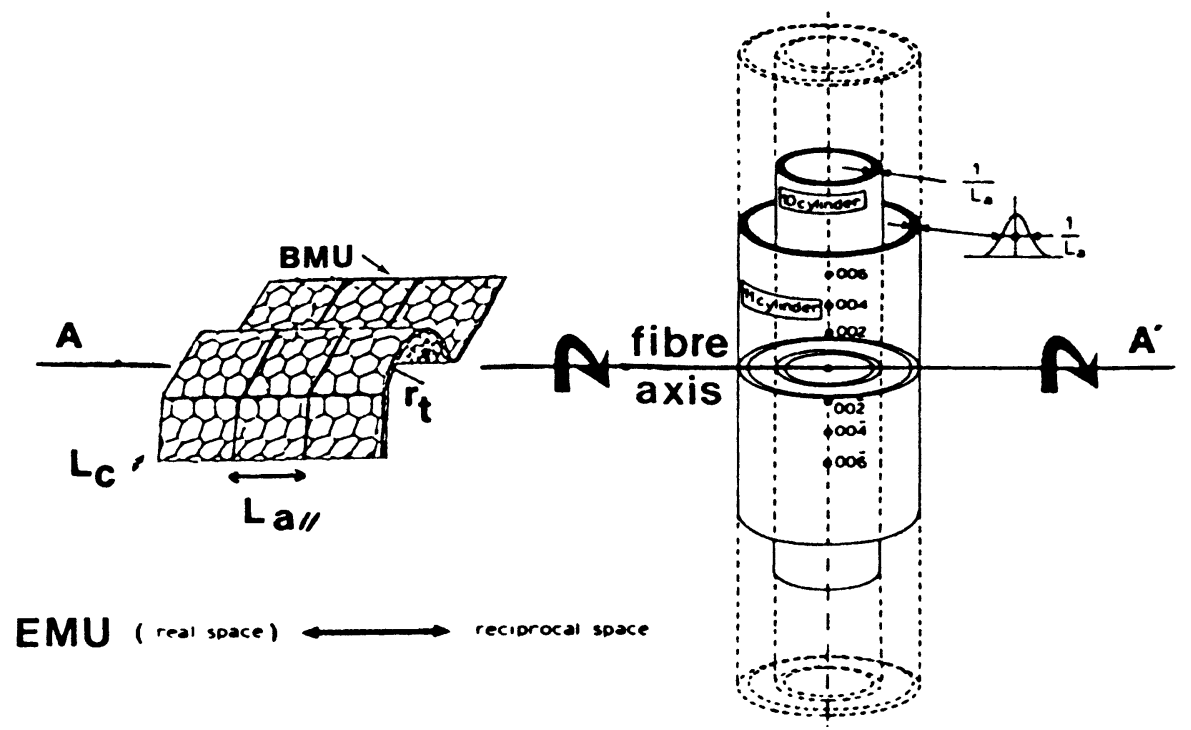

a)

b)

Fig. 2. - a) Basic microtextural units (BMU). b) Reciprocal lattice. 
If the 002 scattered beam and the 000 undeviated beam interfere, lattice fringes are produced. They represent the image of aromatic layers of the carbon fibre in thin sections perpendicular to the fibre axis (transverse section).

From our previous data $[5,6]$ we established a model (Fig. 3). Basic microtextural units (BMU) are linked together with many residual defects in high tensile strength fibres (disclinations, tetrahedral bonds, heteroatoms...). High modulus fibres obey the same model but with a well organized structure due to the heat treatment i.e. with fewer defects. The association of well-organized BMU produces elemental microtextural units (EMU), which present a transverse radius of curvature $R_{\mathrm{t}}$ (Fig. 3.a.). $R_{\mathrm{t}}$ is an important microtextural parameter [6]. The tensile strenght of carbon fibres depends mainly on the value of $R_{\mathrm{t}}$.

a

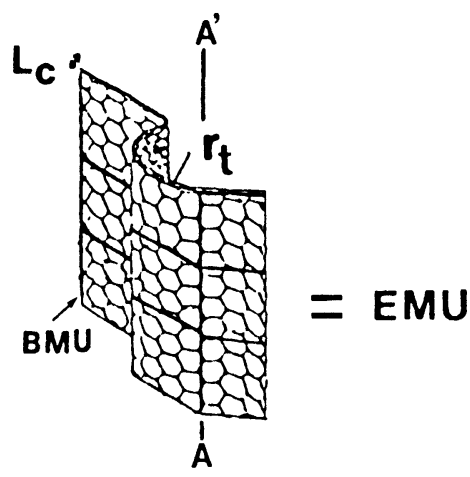

b

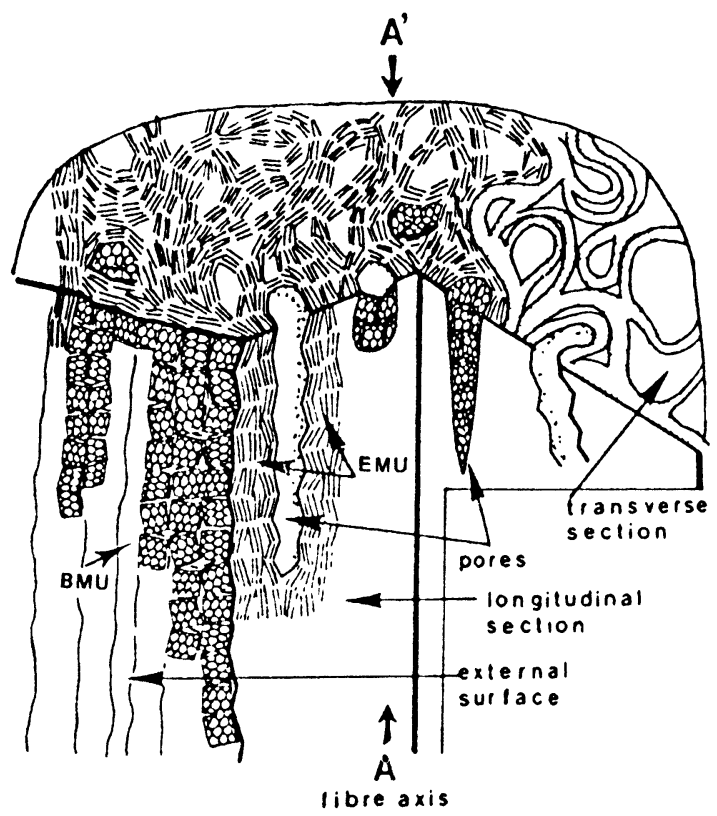

Fig. 3. - a) Elemental microtextural unit (EMU). b) High strength carbon fibre model. 
If we consider the model we note that carbon layers of BMU present either edges or their surfaces as outcropping at the surface of the fibre. Depending on this orientation, the reactivity of carbon layers is different since surfaces of layers are less reactive (consist mostly of saturated bonds) than edges. Obviously, adhesion between fibres and matrix in a composite material depends on this outer morphology.

Hitherto, we have considered that the external surface was built at random with a strong edgesurface distribution for high tensile strength fibres and a strong surface- edge distribution for high modulus ones. At the present time, our studies concerning this point, in progress for new generations of carbon fibres, would seem to prove that large regions with different characteristics exist inside the fibre (Figs. 4 and 5). In figure 4 (high strength fibre) and in figure 5 (high modulus fibre) we see regions of bent carbon layers with radii of curvature $R_{\mathrm{t}}$ equal to 1- $1.5 \mathrm{~nm}$ and 2 $2.5 \mathrm{~nm}$ respectively associated with a region with uncurved layers [5-7]. The junction between these regions is well defined but not understood at the moment. Nevertheless their typical morphology is very important because of their different reactivity at the fibre surface. Fibre-matrix adhesion depends on their mutual presence. Consequently, high tensile strength fibres could promote high adhesion, whereas high modulus fibres are not able to be in contact over a large part of their perimeter.

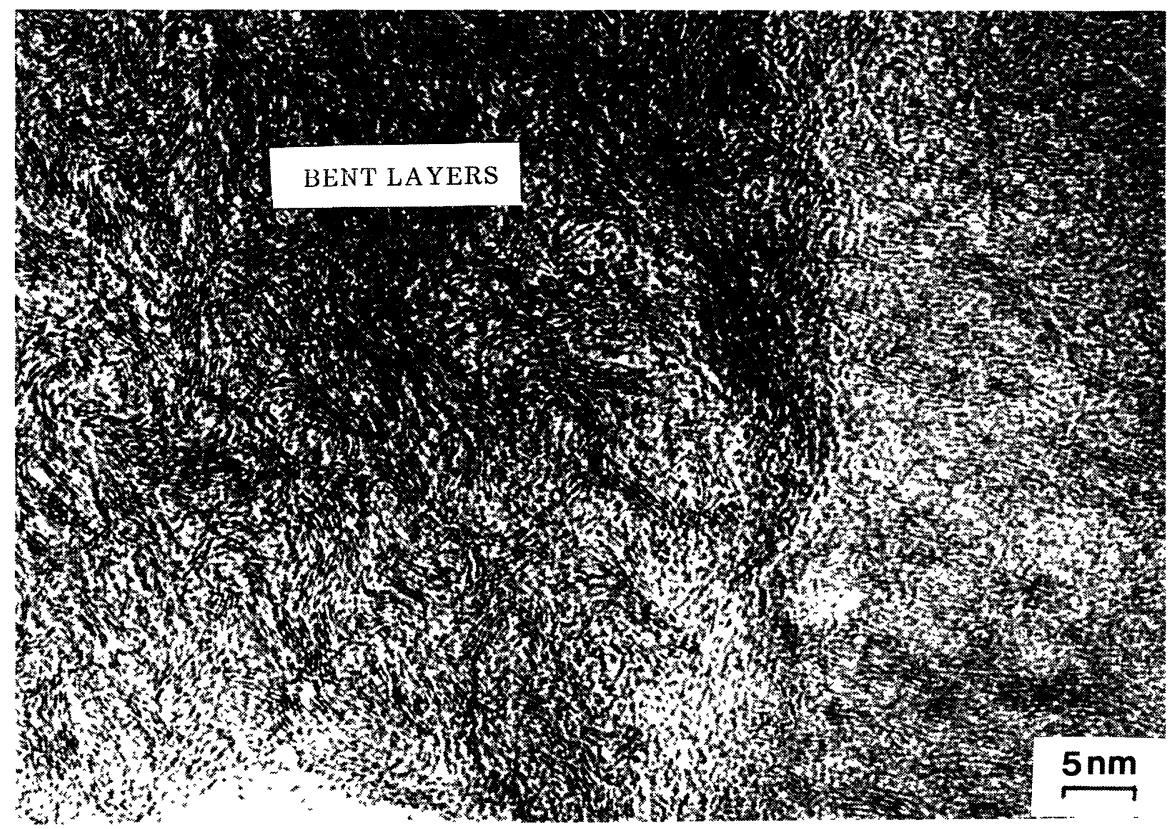

Fig. 4. - Adjacent regions, with bent carbon layers and no curved carbon layers-high tensile strength carbon fibre - Toray $800 \times 2 \times 10^{6}$.

4.2 INTERFACIAL PHENOMENA. - In the case of oxidizing surface treatments the fibre-matrix adhesion is improved by chemical bonds between functional groups $(\mathrm{COH}, \mathrm{COOH})$ of the oxidized fibres and the amino groups coming from the hardener of the resin [8]. 


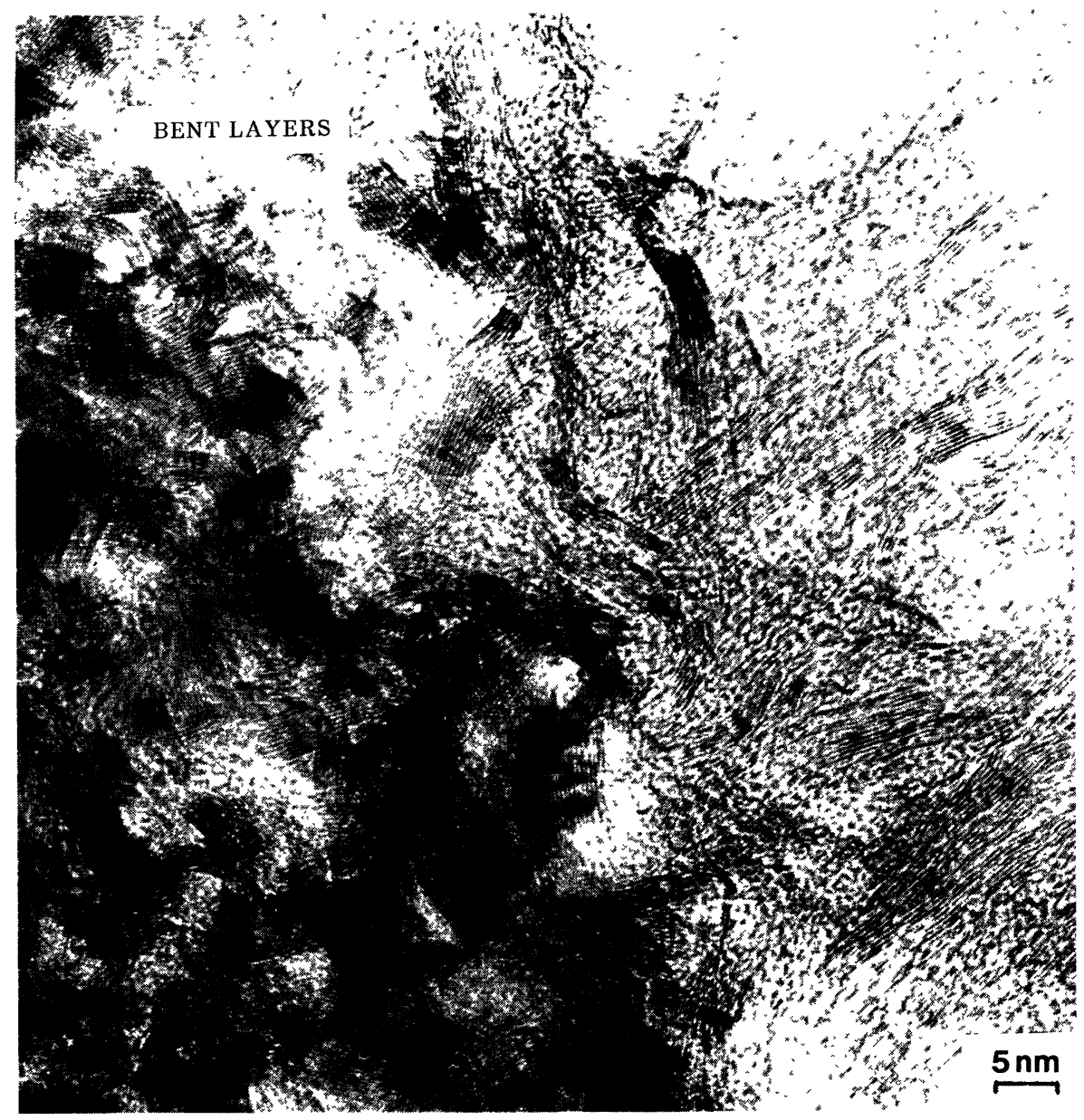

Fig. 5. - Adjacent regions with bent carbon layers and no curved carbon sheets-high modulus carbon fibre - Toray M50 × $2 \times 10^{6}$.

The surface treatments with amino groups (no commercial treatments) are based on the idea that the functional amino groups grafted on the fibre surface have to react directly with the epoxy groups of the resin [9].

4.2.1 Oxidizing treatments. - In the manufacturing process, carbon fibres are oxidized then coated with a sizing agent. The aim of the oxidizing surface treatments is to create reactive carbon layers. Carbon atoms weakly linked are attacked, some chemical groups are fixed $(\mathrm{COH}$, $\mathrm{COOH}, . .$. ) and a microrelief is produced (Fig. 6).

This outer morphology is favorable for a good junction between fibres and matrix [3].

Figure 6 represents a region with curved carbon layers at the surface of the fibre. We observe that the external surface of the fibre is made up of some carbon layers which present their edges for outcropping at the interface. We think that this phenomenon is produced by the chemical treatment. Curved layers are, by their defects (carbon atoms lightly linked), sensitive to all attacks. By relaxation of stresses to some extent, erosion reveals many carbon layer edges, which outcrop at the surface (strong surface treatment), as sketched in figure 7. Probably it is on these sites 


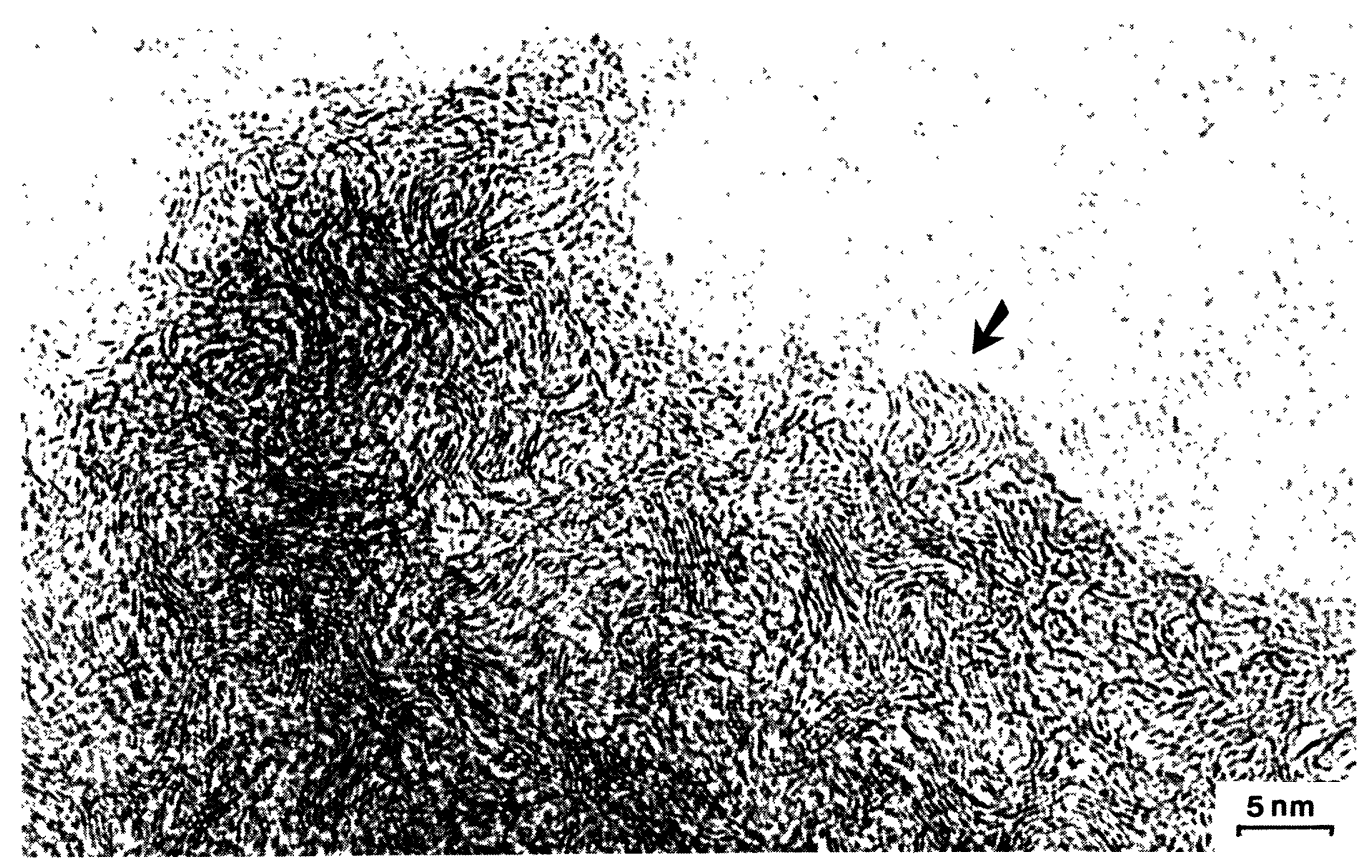

Fig. 6. - Oxidizing surface treatment $\left(\left(\mathrm{NH}_{4}\right)_{2} \mathrm{SO}_{4}\right)$-no sizing- Courtaulds XAU fibre $\times 3 \times 10^{6}$.

(Fig. 6, arrow) that chemical groups are fixed and cause carbon fibres to be more reactive. When the fibres are sized, we detect an interphase between fibre and matrix.(Fig. 8). On the contrary, no interphase is observed when the fibres have no sizing. The thickness of this interphase varies from 10 to $25 \mathrm{~nm}$, it could be connected to the sizing and related to the interphase described by Fitzer [8].

4.2.2 Non oxidizing treatments. - If the surface treatment is well-adapted large regions (curved and not curved) are reactive and are able to promote good adhesion between fibres and matrix.

Figure 9 (hexamethylene tetramine treatment) represents an area with many edges of carbon layers present at the interface (not bent layer). The fibre-matrix interface is diffuse and the adhesion is probably very strong. For high modulus fibres, where the layer surfaces are well organized with few defects, this is the only process available for establishing contact between fibres and matrix.

For treatment carried out in an aqueous solution of urea, large regions having bent carbon layers exist at the junction between fibres and matrix. This is illustrated in figure 10. In such cases, at the surface of the carbon fibre, the convex and faulty areas of curved carbon layers are under tension and consequently are very reactive to a suitable treatment (unstable bonds). The outer carbon layers are therefore, lightly attacked by the chemical treatment. Some bonds are broken and the resulting relaxation of stresses makes carbon layers very reactive (Figs. 7 and 10). Some chemical groups coming from the treatment solution are therefore grafted on the edges of carbon layers. These carbon layers with functional groups are suitably placed for carrying out chemical bondings with the resin (Fig. 10, arrow). In this case, the interface is clear. When the surface treatment is suitable for the fibre, both contributions (edges and surface layers) are able to confer a strong adhesion with the matrix in composite materials. 


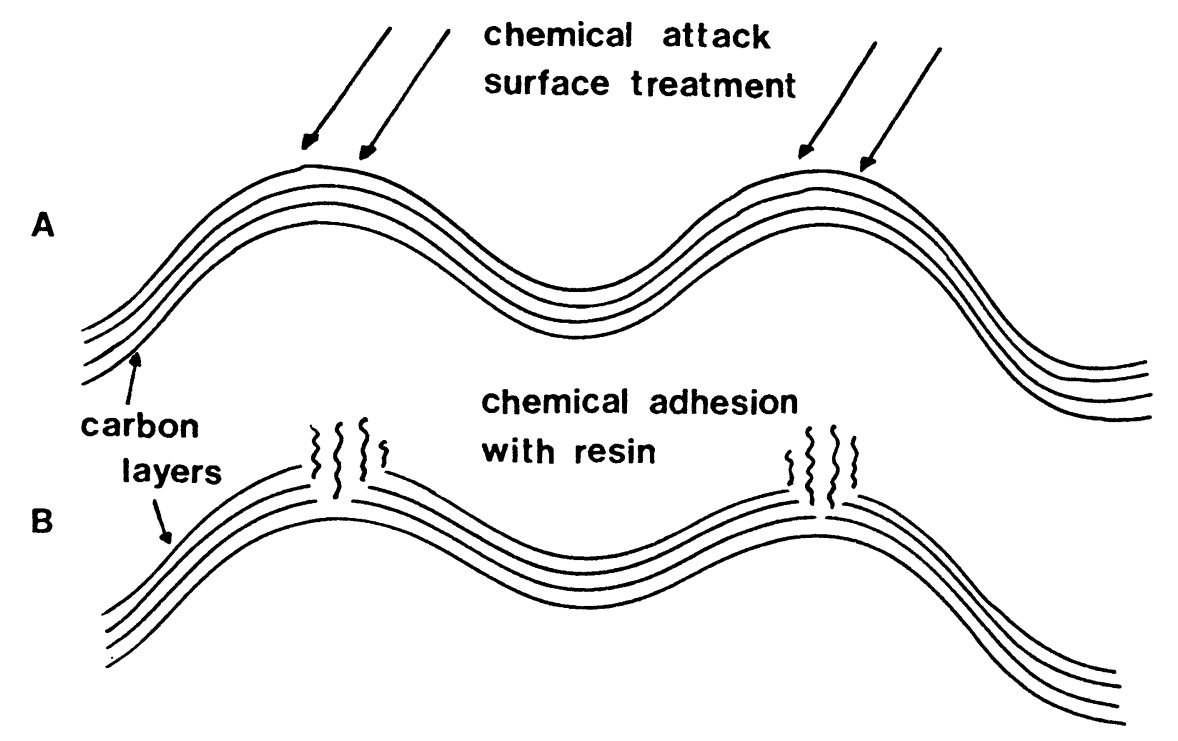

Fig. 7. - a) chemical attack process of bent carbon layers due to surface treatment, b) resulting chemical adhesion with resin.

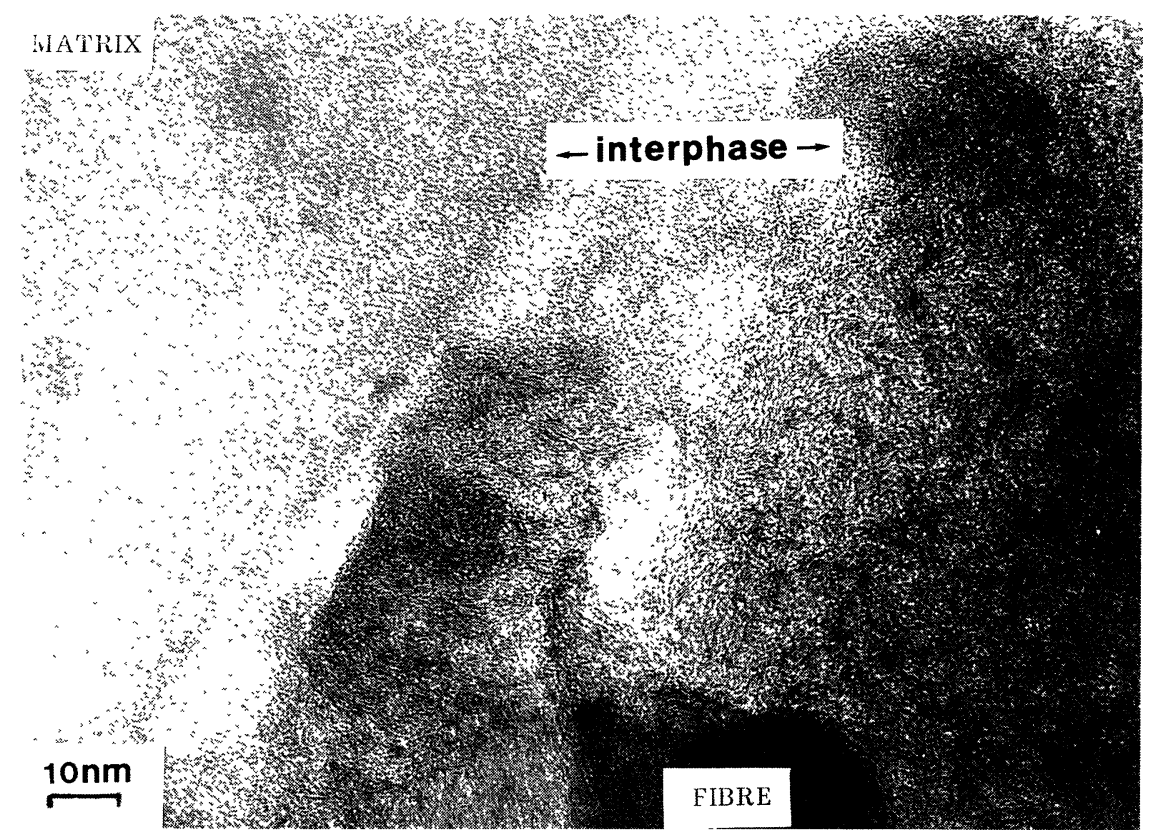

Fig. 8. - Commercial oxidizing surface treatment -sizing $1 \%$ - Courtaulds XAS fibre $\times 10^{6}$.

In the case of an inappropriate surface treatment, a fibre-matrix interface is only produced with carbon layer edges present at the fibre surface (Fig. 11). Thus, contact between fibre and matrix exists only over small areas and numerous decohesions are observed. 


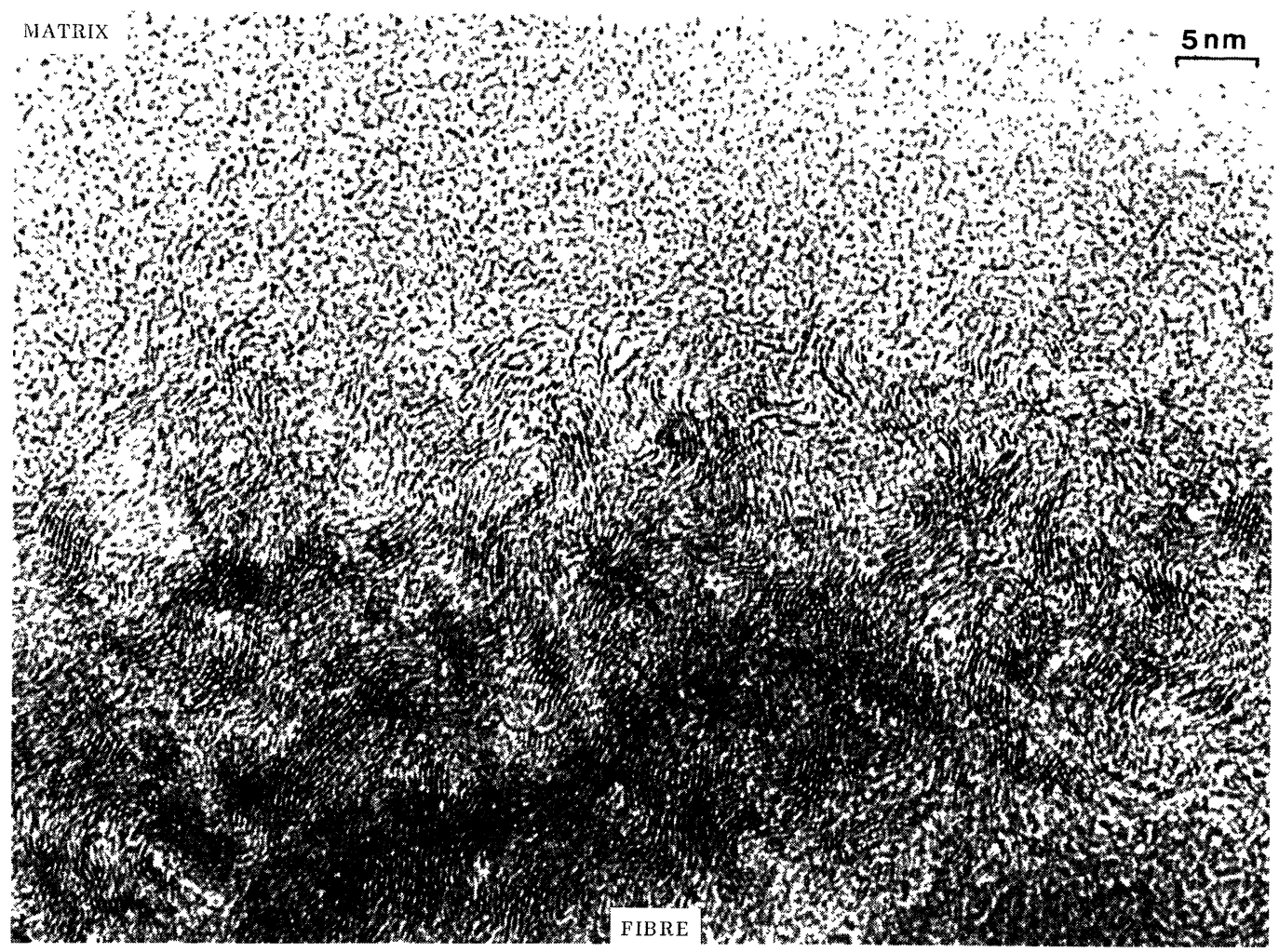

Fig. 9. - Non oxidizing treatment (hexamethylene tetramine) -no sizing- Courtaulds XAU fibre $\times 3 \times 10^{6}$

\section{Discussion. Conclusion.}

The mechanical properties of composites are related to interfacial phenomena [10]. The features of interfaces should be investigated for a given function of a composite because load transfer at the interface depends on the adhesion. The fibre-matrix interpenetration is an essential condition for good adhesion [11]. If we consider a treated carbon fibre surface as a polymer ( $\mathrm{C}, \mathrm{H}, \mathrm{O}$ atoms), the fibre-matrix junction can be studied as the contact between two polymers. This suggests that a high strengh material will be associated with a diffuse interface whereas a resilient material will be related to a clear interface. 


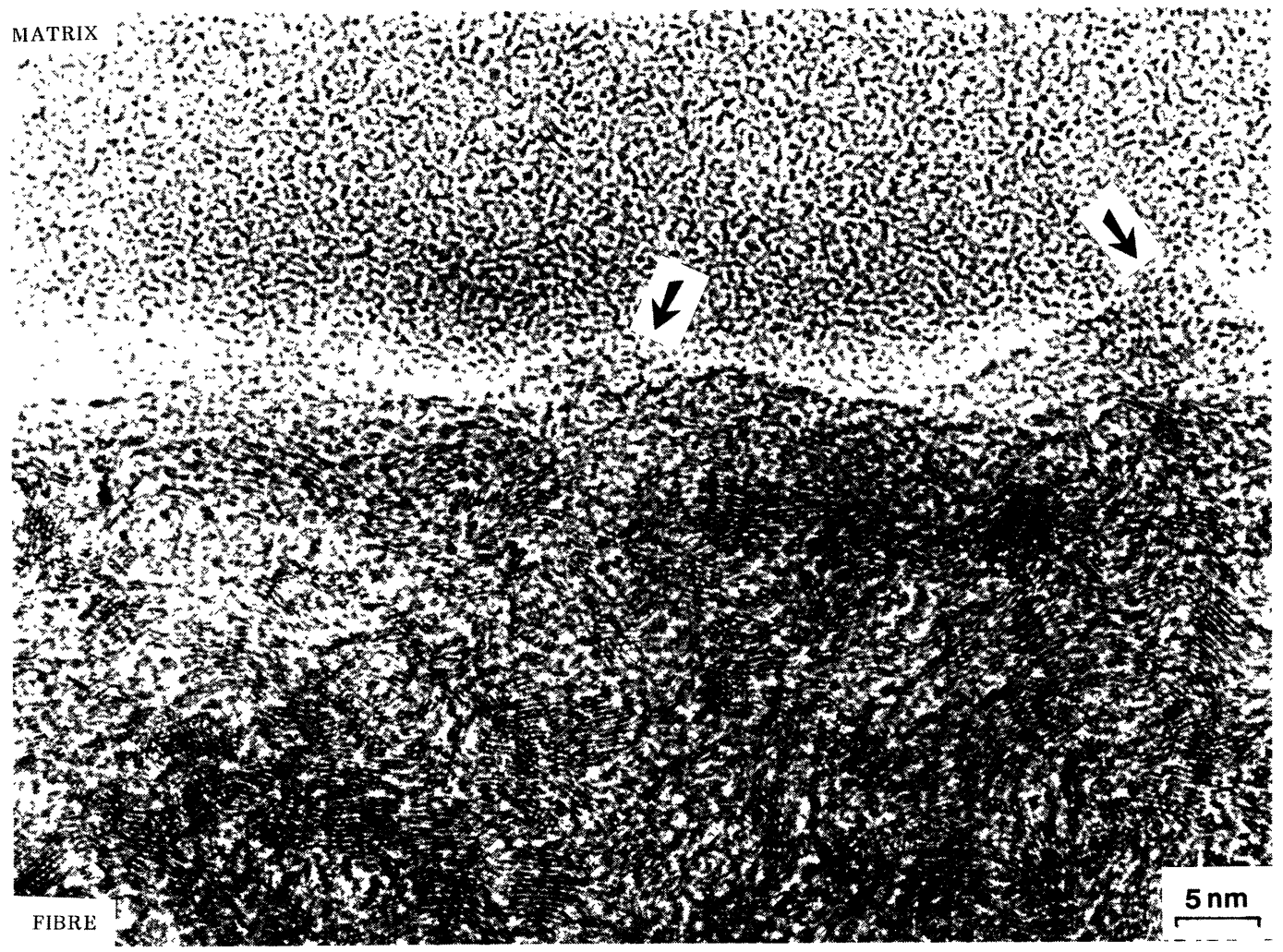

Fig. 10. - Non oxidizing treatment (urea) -no sizing- Courtaulds XAU fibre $\times 3 \times 10^{6}$.

\section{Acknowledgements.}

The author would like to acknowledge the support of DRET and CNRS.

\section{References}

[1] REIMER L., Transmission electron microscopy (Springer Verlag, 1984).

[2] LANNES A. et PEREZ J.Ph., Optique de Fourier en microscopie électronique (Masson,1 1983).

[3] GuIGON M., Proc. 6th intern. Meeting on composites JNC6, J.P. Favre and D. Valentin Eds., Paris (1986) p. 131.

[4] Sanchez M., Desarmot G., Merienne M.C., Barbier B., Proceedings of the 5th National Conference on Composites, JNC5, C. Bathias and D. Menkes Eds. (1986) p. 472. 


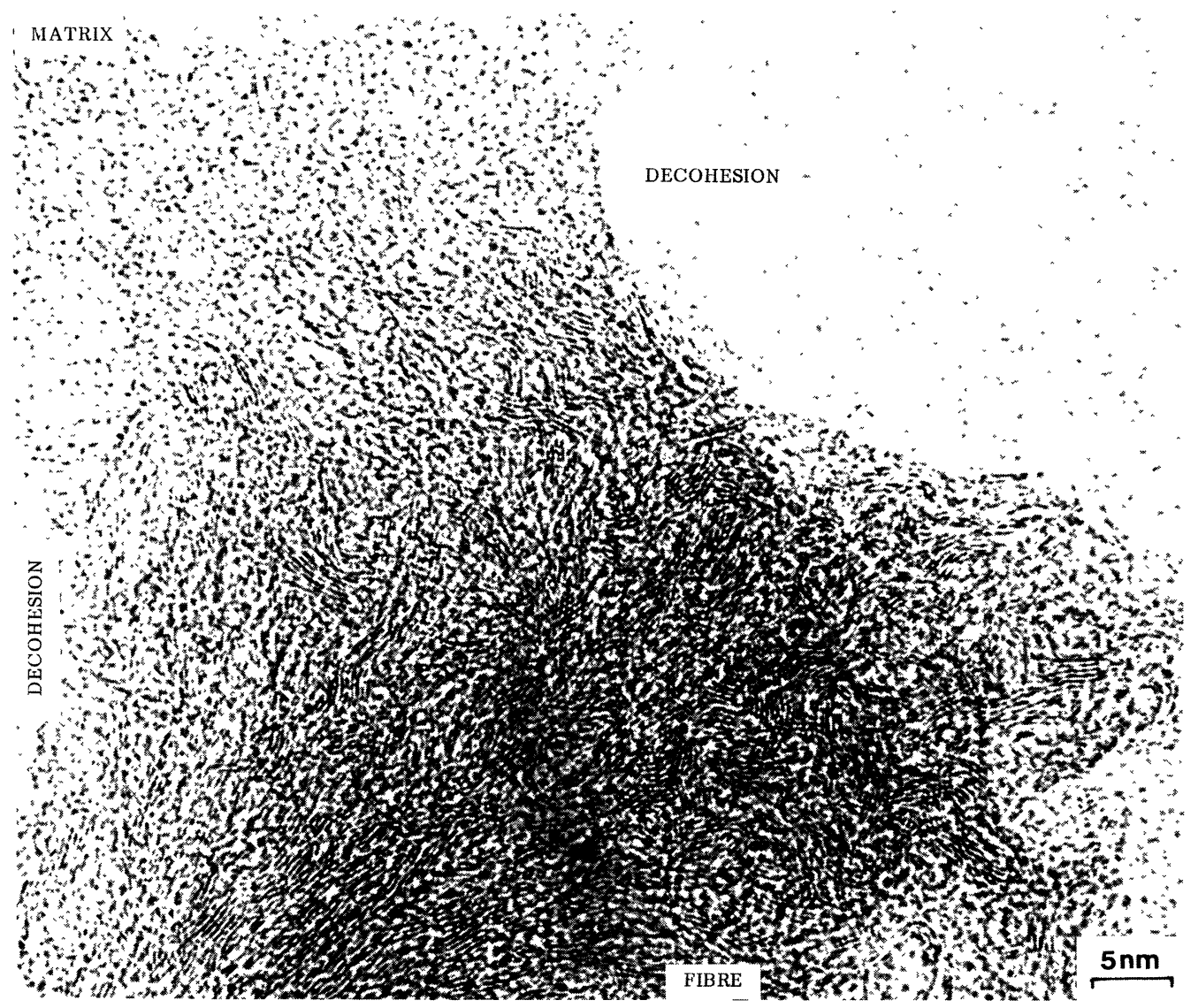

Fig. 11. - non oxidizing treatment -no sizing- Courtaulds XAU fibre $\times 3 \times 10^{6}$.

[5] GUIGON M., OBERLin A. and Desarmot G., Fibre Sci. Technol. 20 (1984) 55 and 177.

[6] GUIGON M., Polymer composite, "Composite 90" (1990) in press.

[7] KLINKLIN E., private communication.

[8] FITZER E., GEIGLE K.M., HutTNER W. and Weiss R., Carbon 18 (1980) 389.

[9] WaltersSON W., Comp. Sci. Tech. 23 (1985) 303.

[10] Proceedings of the international conference on Interfacial phenomena in composite materials, IPCM 89, Sheffield, (1989).

[11] De GenNes P.G., C.R. Acad. Sci. Paris II 308 (1980) 13. 